\title{
AN IDIOSYNCRATIC DECISION SUPPORT SYSTEM FOR CREDIT RISK ANALYSIS OF SMALL AND MEDIUM-SIZED ENTERPRISES
}

\author{
Tânia S. H. GONÇALVES ${ }^{a}$, Fernando A. F. FERREIRA ${ }^{b, c}$, \\ Marjan S. JALALI ${ }^{\mathrm{b}}$, Ieva MEIDUTE்-KAVALIAUSKIENE $\dot{\mathrm{d}}^{\mathrm{d}, \mathrm{e}}$ \\ ${ }^{a}$ School of Management and Technology, Polytechnic Institute of Santarém, \\ Complexo Andaluz, Apartado 295, 2001-904 Santarém, Portugal \\ ${ }^{b}$ ISCTE Business School, BRU-IUL, University Institute of Lisbon, \\ Avenida das Forças Armadas, 1649-026 Lisbon, Portugal \\ ${ }^{c}$ Fogelman College of Business and Economics, University of Memphis, \\ Memphis, TN 38152-3120, USA \\ ${ }^{d}$ Faculty of Business Management, Vilnius Gediminas Technical University, \\ Sauletekio al. 11, LT-10223 Vilnius, Lithuania \\ ${ }^{e} B R U-I U L$, University Institute of Lisbon, Avenida das Forças Armadas, \\ 1649-026 Lisbon, Portugal
}

Received 28 April 2014; accepted 24 January 2015

\begin{abstract}
Small and medium-sized enterprises (SMEs) are currently considered an important driving force of economic growth. Several studies have been developed to analyse this issue and, in particular, to assess the credit risk of SMEs. Most of these applications, however, share the same methodological limitations, such as the manner by which criteria are selected, or the methods used for calculating the weights between them. Based on the integrated use of cognitive mapping techniques and the Interactive Multiple Criteria Decision Making (TODIM) approach, this study aims to create an idiosyncratic decision support system for the identification of multiple criteria and the calculation of their respective weights (i.e. the trade-offs) in the evaluation of SME credit risk. The results show that the model created in this study allows for simple and straightforward credit concession decisions, facilitating the evaluation of SME credit applications through more informed and transparent risk assessments. Practical implications, strengths and weaknesses of the proposed framework are analysed and discussed.
\end{abstract}

Keywords: credit risk analysis, multiple criteria decision analysis (MCDA), small and mediumsized enterprises (SMEs), TODIM (Portuguese acronym for interactive multiple criteria decision making).

JEL Classification: C44, D70, M21.

Corresponding author Fernando A. F. Ferreira

E-mails: fernando.alberto.ferreira@iscte.pt; fernando.ferreira@memphis.edu 


\section{Introduction}

The effects of the most recent financial crisis have been wide reaching. Even the world's most developed economies, especially those in the European Union (EU), were quickly impacted by the downturn and struggled to come up with answers to minimize its effects. One of the many consequences of this economic (and social) crisis was the ensuing difficulty of access to debt markets and shortage in liquidity (Xiao-yan et al. 2012). Faced with such an adverse situation, rescue plans for various EU member states (Portugal among them) were created, as a means to not only protecting the countries themselves, but to ensuring the stability of the euro area and the interests of the EU as a whole. The repercussions of these events quickly became visible in many areas of economic activity, and the financial sector was no exception. In fact, the financial sector has arguably been at the very epicentre of the crisis, facing added difficulties in access to credit markets (i.e. suffering from liquidity shortages), while at the same time having to cope with the pressures of the new responsibilities demanded of it, of banks in particular (Wu 2012).

Small and medium-sized enterprises (SMEs) have also been affected by the deepening crisis (Xiao-yan et al. 2012), some of them severely so; and for many of these firms, bank lending has traditionally served as a facilitator of their economic activity, and a promoter of their ability to generate economic growth (Altman et al. 2010; Gupta et al. 2014b). However, in order for banking to function as a lever of growth in this way, credit concessions need to be accessible, transparent and reliable. Banks can thus play a key role in financing economic systems, for instance through the provision of credit to SMEs; but the manner in which lending decisions are made is critical, particularly in the context of an ongoing financial crisis (cf. Ferreira et al. 2014a).

Credit risk assessment for SMEs is, therefore, paramount for banking institutions, and a variety of statistical techniques have been applied to create credit scoring systems for this purpose; for instance, Linear Discriminant Analysis (LDA), Logistic Regression Analysis (LRA) or Multivariate Adaptive Regression Splines (MARS) (Wang et al. 2011). It should be noted, however, that "the problem with applying these statistical techniques to credit scoring is that some assumptions, such as the multivariate normality assumptions for independent variables, are frequently violated in the practice of credit scoring, which makes these techniques theoretically invalid for finite samples" (Wang et al. 2011: 230). In addition, credit risk assessment is usually based on variables with values that are not fixed, but can rather be presented in differing manners. At the extreme, this means the analysis of this risk can be swayed to the point where there is an impact on whether or not credit is granted. Given these limitations, and because there is no one overall superior technique for building credit scoring models ( $c f$. Wang et al. 2011), the combined use of cognitive mapping with multiple criteria decision analysis (MCDA) tools emerges as a plausible alternative. Together, these tools are able to overcome many of the limitations of previously used models, and can furthermore serve as a decision aid for the selection of the criteria to be used in credit evaluations, and the calculation of their relative weights. Such a multicriteria approach is thus not only feasible, but arguably of great interest to the all-important evaluation of SME credit risk because it allows for greater robustness and transparency in the process 
(i.e. larger number of assessment criteria identified, and greater clarity with regard to their definition and origin).

In past MCDA applications, criteria have typically been defined based on the literature, legislation or questionnaires. Using cognitive mapping to drive this process, however, not only greatly improves understanding of the underlying problem but also generally allows for a wider range of criteria to be included in the assessment system. In this sense, cognitive mapping was used to identify the most important determinants of credit risk evaluations, and so helped to reduce the number of omitted criteria in the decision process (see Eden, Ackermann 2004). TODIM (the Portuguese acronym for Interactive and Multicriteria Decision Making) was chosen due to its proven track record in similar studies on risk analysis (Rangel, Gomes 2007; Gomes, Rangel 2009; Pereira et al. 2013), and because of the technique's fit with the constructivist approach adopted in this research. Together, these procedures should allow for a more complete definition of evaluation criteria, as well as for the calculation of the trade-offs between them. Their application requires the input of a body of professionals; and in this sense, a group of banking professionals specializing in lending to SMEs was brought together to structure the analysis of the problem. Subsequently, evaluation criteria and their respective trade-offs were defined, and the results obtained were discussed with the professionals and analysed for consistency. The aim was to obtain a framework adjusted to the reality of credit concessions to SMEs, able to make ratings for credit purposes as simple and transparent as possible.

Following this, the main aim of this study is thus the development of a multiple criteria decision support system for SME credit risk assessments, which integrates cognitive maps with the TODIM technique, known for its relevance and suitability to risk analyses. To the best of our knowledge, this is the first integrated application of cognitive mapping with the TODIM tool in the context of risk of assessment of SME credit applications. Indeed, the relevance of using OR (Operational Research) techniques to develop performance assessment systems in such a manner has long been argued (cf. Santos et al. 2002; Ferreira et al. 2011; Amado et al. 2012).

In addition to this introduction, this paper contains four additional sections. Section 1 addresses the importance of risk assessments in SME credit applications, as well as some of the main limitations of the most commonly used valuation models. Section 2 presents the methodological framework of the evaluation system developed in this study, expounding the manner in which cognitive maps can be combined with TODIM to overcome some of the previously identified limitations of existing models. Section 3 explains the procedures whereby multiple criteria for the evaluation of SME credit risk were identified and evaluated, and the final section presents our conclusions.

\section{Related work}

The current economic context has made the evaluation of credit applications in the banking sector more vital than ever (cf. Costa 2004b; Altman, Sabato 2007; Ferreira et al. 2013). Financial institutions have become increasingly cautious in their analyses of the assumptions that underpin credit applications by SMEs, and are simultaneously showing greater 
concern with the implications of potential credit approvals (Ferreira et al. 2014c). Indeed, it is widely agreed that in the current economic climate, credit risk assessment plays a key role for banking institutions, SMEs and, as a result, country economies and economic growth as a whole. Such assessments require that financial institutions carefully analyse the underlying assumptions of credit applications, as well as the implications entailed by their acceptance (Ferreira et al. 2013). As a starting point, a detailed analysis is necessary, to ensure the existence of baseline conditions for credit concession, and a solid foundation of trust between the SME and the financial institution. To build upon this, however, and ensure that credit can be granted, support conditions need to be created and the trust between the institutions fostered. In this sense, developing an assessment model, which can allow credit providers to make transparent decisions, can be of crucial importance.

In practical terms, credit concessions signify the provision of a monetary value subject to a promise that the amount will be repaid in full (plus interest); and this in turn requires confidence in the solvency of the debtor - the company's capability to honour these commitments on the agreed dates. Associated to this decision process regarding a credit concession (or its refusal) is credit risk; i.e. the risk of loss incurred if the debtor cannot offer a commensurate counterpart to the credit concession (Xiao-yan et al. 2012; Ferreira et al. 2013). This risk is closely related to factors both within and outside of the company, which can adversely affect its ability to repay the amount owed. Generally speaking, the most serious risk factors are finance-related, and may result from changes in the economic environment (e.g. interest rates, exchange rates, inflation) and the manner of functioning of the entities with which the company has established some form of cooperation. According to Altman and Saunders (1998), the three main forces influencing the risk of lending are: (1) the rising number of bankruptcies worldwide; (2) the increasingly competitive margins on loans; and (3) the asset depreciation occurring in many markets.

Although "financial researchers have already determined that financial risks constitute the underlying basis of every financial decision problem, the management of such risks still remains a challenging issue" (Doumpos, Zopounidis 2001: 97). The assessment of credit risk is thus one of the most critical and decisive moments in the process of credit concessions and can, in fact, determine whether or not credit should be granted. As such, improving credit risk assessment systems can be expected to contribute to more accurate concession decisions, and to lower the levels of risk associated with loans (Lopez, Saidenberg 2000; Gupta et al. 2014b).

The development of a robust variety of evaluation systems has resulted in significant improvements in the assessment of credit applications in recent years (for a categorized review, see Gupta et al. 2014a). These evaluation tools, commonly known as credit scoring systems, allow credit providers to make more informed and assertive decisions. According to Chaia (2003), when adequately developed and applied, credit scoring can bring relevant benefits to financial institutions. Indeed, "credit scoring has become one of the primary ways for financial institutions to assess credit risk, improve cash flow, reduce possible risks and make managerial decisions" (Wang et al. 2011: 223).

The credit risk assessment systems developed to date are not, however, without limitations. According to Costa (2004a) and Campbell et al. (2008), many of these result from a common problem: lack of access to all relevant information. As confirmed by Wang et al. 
(2011), not all the agents involved in such processes know (or they know only imperfectly) the procedures followed in assessing credit risk. Furthermore, there is often a lack of clarity with regard to the manner in which the various evaluation criteria included in the risk assessment process should be weighted. Lopez and Saidenberg (2000: 152) note that "these limitations create a serious difficulty for users' own validation of credit risk models and for validation by third parties, such as external auditors or bank regulators". Therefore, the discussion has not been put to rest and there is a need for the development and/or adoption of new models, techniques or approaches, which might help overcome the limitations presented by the most commonly used valuation models (Gupta et al. 2014a). Accordingly, by making complementary use of cognitive mapping techniques with TODIM, the main objective of the current study is the development of a multicriteria system, which can allow the process of credit risk assessment for SMEs to become more informed, transparent and comprehensive.

Cognitive maps have been applied in numerous studies and are important tools for the structuring of complex problems. TODIM, in turn, not only has a proven track record of successful applications to the study of risk analysis, but also fits well within the constructivist nature of the MCDA approach (Gomes, Rangel 2009; Pereira et al. 2013). Thus, the proposed aim of a methodological advance in lending risk assessments through a muticriteria approach seems not only feasible but also of great utility to achieving such assessments with greater robustness and transparency. Against the backdrop of the current economic situation, and the uncertainty that will always exist in deciding whether or not to grant credit to an SME, an MCDA approach can potentiate more informed decisions. At a time when credit constraints are becoming increasingly tight, such an approach is endowed with particular interest and relevance ( $c f$. Zavadskas, Turkis 2011). The next section presents the methodological framework of the study.

\section{Methodological background}

The current study is grounded on the fundamental convictions of the MCDA approach ( $c f$. Belton, Stewart 2002). As noted by Bana e Costa et al. (1997), this approach emerged from the need to operationalize concepts in a way that would enable decision makers to articulate several different, and possibly even conflicting, points of view. The MCDA framework is therefore an open field of research ( $c f$. Bana e Costa et al. 1997), which recognizes the limits of mathematical optimization, and aims to build something new, rather than preexistent; i.e. a framework that allows the beliefs, value systems and objectives of the decision makers themselves to be worked with. The MCDA approach can thus be designated as "constructivist"; it provides decision makers with tools which can facilitate the decision process, and enables them to "capture, analyse and understand these points of view, in order to be able to find the way in which the decision process must be handled" (Mateu 2002: 10).

Given the instability of the current economic climate, and the uncertainty underlying credit concession decisions, an MCDA approach therefore has the potential to lead to more informed decisions (Ackermann, Eden 2001; Belton, Stewart 2002), and to allow problems to be analysed in a structured and meaningful way. As such, it offers advantages vis-a-vis alternative methods in the assessment of credit applications by SMEs. 


\subsection{Cognitive maps}

Cognitive maps are presented in the literature as a tool for structuring complex problems, which is interactive, versatile and simple to use ( $c f$. Ackermann, Eden 2001; Eden, Ackermann 2004; Montibeller, Belton 2006; Carlucci et al. 2013). They can be used to: (1) promote discussion among the decision makers; (2) reduce the rate of omission of important criteria; and (3) increase learning, based on a deeper understanding of the cause-and-effect relationships between criteria ( $c f$. Ferreira et al. 2014b). Once a particular problem has been analysed, a cognitive map can be built based on the representations created by the decision makers, with the support of a facilitator (i.e. researcher/scientist).

A commonly used approach to the construction of cognitive maps is the Strategic Options Development and Analysis (SODA) methodology, originally developed by Colin Eden with the purpose of supporting stakeholders in the structuring of complex decision problems. This methodology allows ideas to be structured, easily visualized, and reorganized as necessary ( $c f$. Eden 1994; Ackermann, Eden 2001). According to Eden and Ackermann (2001), the SODA approach aids and supports the structuring of complex problems by effectively acting as a mediator in decision-making discussions. In addition, it helps construct a model that belongs to the group as a whole, but at the same time contains the individual considerations of each participant. Because they are rooted in constructivism, cognitive maps are furthermore flexible and iterative. As such, it was expected that the application of the SODA methodology in this study would result in a consensual collective cognitive map, derived from the discussions among the decision makers, and constitute an advantageous tool for the structuring of such a complex problem.

\subsection{The TODIM approach}

The TODIM approach, created in the early 1990s by Luiz Flávio Autran Monteiro Gomes, is a multicriteria evaluation technique based on Prospect Theory ( $c f$. Gomes, Lima 1991; Rangel, Gomes 2007; Gomes, Rangel 2009; Ribeiro et al. 2012). Prospect Theory, developed by Khaneman and Tversky in the early 1980s, was intended for the modelling of human behaviour in decision situations involving risk (cf. Kahneman, Tversky 1979; Silva et al. 2011). It earned its authors the Nobel Prize for Economics in 2002. As expounded by Rangel and Gomes (2007), Prospect Theory proposes an S-shaped value function to explain both risk aversion and propensity towards risk (see Fig. 1).

While other multicriteria methods are based on the assumption that decision makers seek to maximize utility or value, TODIM makes use of a global measure of value, which is calculated by applying the paradigm of Prospect Theory to test specific loss and gain functions ( $c f$. Gomes, Rangel 2009). Once empirically validated, these functions serve as the foundation for the construction of an additive difference function, which provides the level of dominance of any given alternative vis-a-vis another. As potential inconsistencies can occur, the TODIM technique possesses a feature that allows the consistence of the value judgments to be analysed, leading to an initial matrix of consistent value judgments (cf. Pereira et al. 2013). 


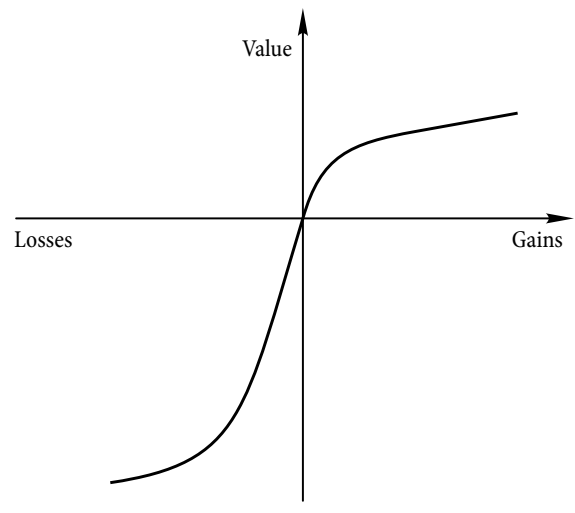

Fig. 1. TODIM value function

Source: Gomes and Rangel (2009: 206).

Once this matrix has been constructed and freed of inconsistencies, the weights of the criteria are defined, and the decision makers are asked to estimate, for each evaluation criterion $c$, how much each alternative $i$ contributes to the objective associated with that criterion. This method requires the valuation measures to be numerical and standardized. After the alternatives have been assessed with respect to all the criteria, an evaluation matrix is obtained composed of numerical values. These values are then standardized; for instance, by dividing the value of an alternative by the sum of the values of all the alternatives. This standardization is carried out for all the criteria, and results charted in a matrix in which all values range between 0 and 1 . This matrix is known as the matrix of partial desirabilities $W=\left[W_{n m}\right]$ (see Table 1 ).

Table 1. Matrix of partial desirabilities

\begin{tabular}{ccccccc}
\hline \multirow{2}{*}{ Alternatives } & \multicolumn{7}{c}{ Criteria } \\
\cline { 2 - 7 } & $C_{1}$ & $C_{2}$ & $\ldots$ & $C_{i}$ & $\ldots$ & $C_{m}$ \\
\hline$A_{1}$ & $W_{11}$ & $W_{12}$ & $\ldots$ & $W_{1 i}$ & $\ldots$ & $W_{1 m}$ \\
\hline$A_{2}$ & $W_{21}$ & $W_{22}$ & $\ldots$ & $W_{2 i}$ & $\ldots$ & $W_{2 m}$ \\
\hline$\ldots$ & $\ldots$ & $\ldots$ & $\ldots$ & $\ldots$ & $\ldots$ & $\ldots$ \\
\hline $\mathrm{A}_{\mathrm{i}}$ & $W_{i 1}$ & $W_{i 2}$ & $\ldots$ & $W_{i i}$ & $\ldots$ & $W_{i m}$ \\
\hline$\ldots$ & $\ldots$ & $\ldots$ & $\ldots$ & $\ldots$ & $\ldots$ & $\ldots$ \\
\hline $\mathrm{A}_{\mathrm{n}}$ & $W_{n 1}$ & $W_{n 2}$ & $\ldots$ & $W_{n i}$ & $\ldots$ & $W_{n m}$ \\
\hline
\end{tabular}

Having obtained the matrix of partial desirabilities, two further matrices are then calculated: the partial dominance matrix and the final dominance matrix. The measure of dominance for each alternative $i$ over each alternative $j$ is given by the following mathematical formula (1) (cf. Gomes, Rangel 2009):

$$
\partial(i, j)=\sum_{c=1}^{m} \varnothing_{c}(i, j), \forall(i, j),
$$

where:

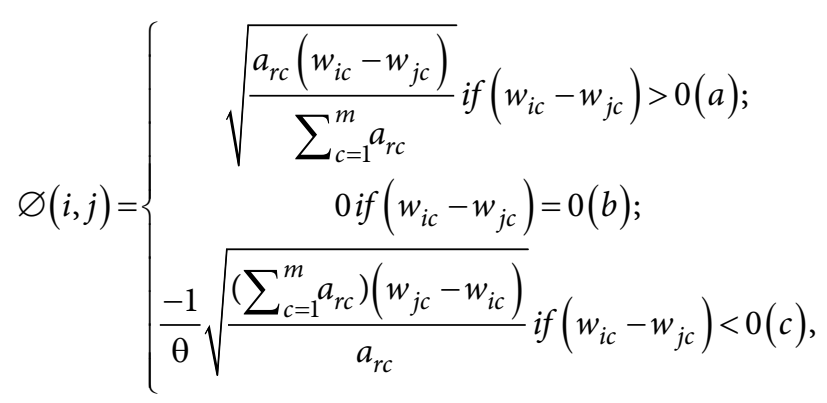


and: $(i, j)$ represents the level of dominance of alternative $i$ over alternative $j ; m$ is the number of criteria; $c$ is a given criterion, for $c=1, \ldots, m$; $a_{r c}$ is the substitution rate of criterion $c$ by the reference criterion $r ; w_{i c}$ and $w_{i c}$ are the weights of $i$ and $j$ respectively in relation to $c$; $\theta$ is the attenuation factor for the losses.

The final dominance matrix is then normalized using formula (3) (cf. Gomes, Rangel 2009), to obtain the global value for each alternative. These values should be interpreted as a measure of desirability or global utility; i.e. as the value of a given alternative, meaning that the alternatives can then be ordered according to their respective values.

$$
\aleph=\frac{\sum_{j=1}^{n} \partial(i, j)-\min \sum_{j=1}^{n} \partial(i, j)}{\max \sum_{j=1}^{n} \partial(i, j)-\min \sum_{j=1}^{n} \partial(i, j)} .
$$

TODIM thus possesses several advantages in relation to other multicriteria decision support tools, such as the fact that it takes risk (i.e. decision makers' value functions in risk situations, as per Prospect Theory) into account. In the next section, we will describe how, through the integrated use of cognitive maps and the TODIM technique, we were able to develop a support system for the identification and operationalization of multiple evaluation criteria for SME credit requests.

\section{Model development}

\subsection{The structuring phase}

The structuring of the model developed in this study was based on cognitive mapping techniques, namely following the SODA approach. This required us to bring together a group of decision makers for face-to-face sessions. Given the limited availability of SME credit specialists for such efforts, a 3-person panel was formed, with bankers specializing in loans to SMEs. Although this may appear like a small number, it has been argued that in applying SODA, "the consultant [i.e. facilitator] will relate personally to a small number (say, three to ten persons)" (Eden, Ackermann 2001: 22). In addition, also present in the sessions were two facilitators (i.e. researchers), responsible for steering the negotiation process, as well as registering the results.

The first group session started with a presentation of the main goal of the study, as well as an explanation of the main concepts and procedures of the SODA methodology. After this introduction, and in order to focus interest and discussion among the decision makers on credit concessions to SMEs, the following trigger question was posed: "Based on your values and professional experience, what are the factors and/or determinants that influence whether or not a loan is granted to an SME?". Having presented and clarified this central question, we proceeded to the application of the "post-its technique". This technique consists of writing on post-its the criteria which, from each decision maker's point of view, are the most important with regard to the decision situation at hand. As the criteria were being referred, the panel members would discuss them, sharing their personal values and experiences. This allowed an understanding of why each criterion was being referenced, and 
what its influence might be when a credit request is being analysed. Some of the decision experts expressed concerns at this stage regarding the repetition of criteria. However, it was clarified that in a second phase of the process, it would be possible to detect such duplications and remove them ( $c f$. Ferreira 2011). The participants were then asked to group the criteria in broad areas of concern, termed clusters, of which five resulted. Their next task was then to focus on each cluster individually, and together deliberate and appraise the relationships of influence or causality between the criteria, and thus establish a hierarchy of criteria within each cluster. Once this step had been completed, the Decision Explorer software (http://www.banxia.com) was used to conceive the group's cognitive map, which served as a support for the following stage of problem structuring (Fig. 2).

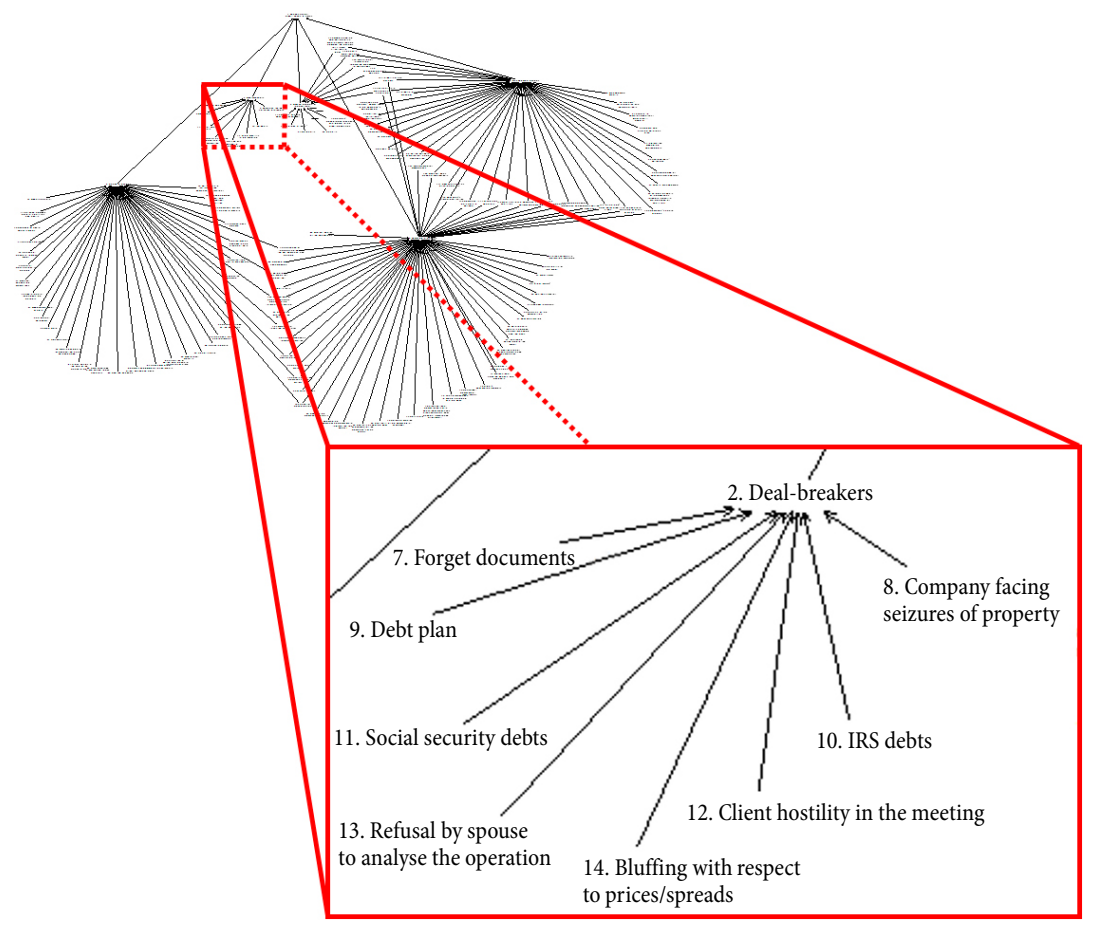

Fig. 2. Final version of the collective/strategic map

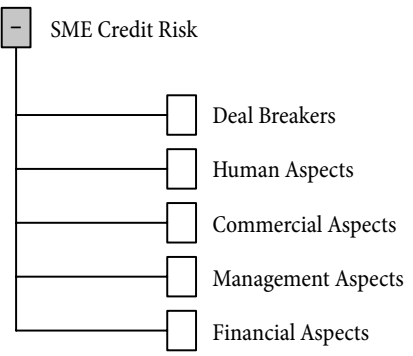

Fig. 3. Tree of points of view
Figure 2 is illustrative of the size of the map, which was composed of approximately 120 interrelated criteria. After analysing this group map, the decision makers defined the hierarchy of criteria (CTRs), from which a value tree was created (Fig. 3). Tests of preferential independence between the CTRs were carried out in order to validate this structure (see Ferreira (2011) for technical details).

It is worth noting that, according to the group's own interpretation of the tree, CTR1 - Deal Breakers - in- 
cludes any negative information that can put the credit concession at risk, namely IRS and Social Security debts. CTR2 - Human Aspects - addresses issues regarding the human characteristics of the SME manager. It seeks to introduce evaluation references such as honesty, friendliness and ethical posture. CTR3 - Commercial Aspects - is associated with the commercial performance of the SME (e.g. sector of activity, purpose of the credit request and operational cost). CTR4 - Management Aspects - addresses issues related to management experience and technical skills within the SME. Finally, CTR5 - Financial Aspects - concerns issues related to the SME's capacity to repay the loan.

In the second group session, the participants focused their attention on the value tree in order to create a descriptor and respective impact levels for each CTR. For illustrative purposes, Table 2 presents the descriptor for CTR1, which resulted from the negotiation process and discussion established between the decision makers.

Table 2. Descriptor and impact levels for CTR1

\begin{tabular}{|c|c|c|c|c|}
\hline \multicolumn{3}{|c|}{ Descriptor CRT1 } & Level & Description \\
\hline Forged Documents & 12345678 & No Forged Documents & Good & Sum $\mathrm{DB}=40$ \\
\hline Seizures of Property & 12345678 & No Seizures of Property & Neutral & Sum DB $\in[36-39]$ \\
\hline IRS Debts & 12345678 & No IRS Debts & L3 & Sum DB $\in[5-35]$ \\
\hline Social Security Debts & 12345678 & No Social Security Debts & & \\
\hline Debt Plan & 12345678 & No Debt Plan [No need] & & \\
\hline
\end{tabular}

In practice, the decision makers identified, for each cluster, the five or six criteria that in their perspective were the most relevant. An adapted version of Fiedler's scale (1965, 1967) was then used to define the levels of partial performance and the reference levels for each descriptor. The descriptors could be qualitative, quantitative or mixed (Ferreira 2011), which facilitated the operationalization of this step. With regard to impact levels, $L_{1}$ is the one with the highest partial performance, while $L_{n}$ represents the lowest performance level. Having defined descriptors for all CTRs in the model, the structuring phase was complete.

Because many hours were required, and given the participants' limited availability, the work sessions turned out to be quite intense. Nonetheless, the process presented itself with a number of virtues, such as the interactivity and dynamism of the techniques used, their flexibility and ease of application. The participants reflected positively on the cognitive map, which in their perspective allowed the inclusion of criteria, which are often forgotten or omitted in current valuation models.

\subsection{The evaluation phase}

The evaluation phase was carried out in the second stage of the second group session. Its first step consisted in filling in a matrix of parity comparisons so that the CTRs could be ordered. The participants were asked to concentrate on the CTRs and tabulate them according to their level of global preference, attributing a value of " 1 " to a criterion that was deemed globally preferable to another; and a value of " 0 " when the opposite occurred. The 
ranking of the CTRs was obtained from the sum of the values attributed in each pairwise comparison, and the final hierarchy was analysed and validated by the panel members. Table 3 represents this final matrix.

Once this stage had been concluded and the hierarchy of CTRs approved, we proceeded to the construction of a new matrix of pairwise comparisons, with the aim of obtaining the trade-offs (weights or substitution rates) between the five CTRs. The group was asked to judge the preferential differences between the CTRs by applying the Analytical Hierarchy Process (AHP) scale (Saaty 1980). Table 4 presents the comparisons made, as well as the weights obtained, all of which were analysed, discussed and validated by the decision makers.

Table 3. CTR order matrix

\begin{tabular}{lcccccccc}
\hline & & CTR1 & CTR2 & CTR3 & CTR4 & CTR5 & Total & Ranking \\
\hline Deal Breakers & CTR1 & & 1 & 1 & 1 & 1 & 4 & 1 \\
\hline Human Aspects & CTR2 & 0 & & 0 & 0 & 0 & 0 & 5 \\
\hline Commercial Aspects & CTR3 & 0 & 1 & & 1 & 0 & 2 & 3 \\
\hline Management Aspects & CTR4 & 0 & 1 & 0 & & 0 & 1 & 4 \\
\hline Financial Aspects & CTR5 & 0 & 1 & 1 & 1 & & 3 & 2 \\
\hline
\end{tabular}

Table 4. Matrix of pairwise comparisons and trade-offs

\begin{tabular}{llcccccc}
\hline & & CTR1 & CTR5 & CTR3 & CTR4 & CTR2 & Weight \\
\hline Deal Breakers & CTR1 & & 3.0 & 4.0 & 4.5 & 7.0 & 0.47999 \\
\hline Financial Aspects & CTR5 & & & 2 & 3.5 & 6.0 & 0.24210 \\
\hline Commercial Aspects & CTR3 & & & 2.0 & 5.0 & 0.14867 \\
\hline Management Aspects & CTR4 & & & & 3.0 & 0.08892 \\
\hline Human Aspects & CTR2 & & & & & 0.04032 \\
\hline
\end{tabular}

As a final step, the model was then tested through practical application. In order to do this, an external collaborator from the banking industry was asked, under conditions of strict confidentiality and anonymity, to provide the researchers with historical information on loan requests by SMEs. The aim was to assess these requests on each of the previously defined CTRs. The results and conclusions of this exercise, which constituted the recommendation phase of the process, are presented in the next section.

\subsection{Testing the "new" model and formulating recommendations}

As noted above, the model created in this study was tested through its application to real credit loan applications by SMEs. The decision makers noted that the assessment of these applications would differ according to the term of the credit, and so the applications were split into short- and long-term requests. The partial evaluation of each request was based on the impact level of each CTR as defined in the structuring phase. 
Five short-term and five long-term credit requests were considered. It is worth noting that while this number is not large, due to the inherent difficulties in obtaining loan application data, the accuracy and precision of MCDA models such as that developed here tends to increase with the introduction of new data. This is a reflection of the constructivist nature of the framework, which is process-oriented and aims to foster learning, rather than looking for optimal solutions. The model developed here was based on the participants' own value systems and experience, and could through this sample of applications be validated by them. Table 5 provides information regarding five short-term credit requests, identified as Delta 1 through to Delta 5.

Table 5. SMEs with pending credit requests (short-term)

\begin{tabular}{cccccc}
\hline \multicolumn{7}{c}{ SMEs with Pending Credit Requests (Short-Term) } \\
\hline ID Deltas & CTR1 & CTR2 & CTR3 & CTR4 & CTR5 \\
\hline Delta 1 & L1 & L2 & L4 & L2 & L3 \\
\hline Delta 2 & L1 & L2 & L3 & L3 & L3 \\
\hline Delta 3 & L1 & L2 & L3 & L2 & L4 \\
\hline Delta 4 & L1 & L3 & L2 & L3 & L2 \\
\hline Delta 5 & L1 & L2 & L2 & L4 & L2 \\
\hline Good & L1 & L2 & L2 & L2 & L2 \\
\hline Neutral & L2 & L3 & L4 & L3 & L3
\end{tabular}

Deltas Good and Neutral represent fictitious credit requests, which were introduced in the model in order to cognitively simplify comparisons (Ferreira et al. 2014b). In conformity with the flexibility of the model described above, as new data is continuously entered into the framework and its predictive power is improved, these fictitious credit requests created to obtain baseline levels of Good and Neutral can be replaced by actual credit requests. It is worth noting that this makes our proposal quite distinct from "traditional" models using existing data, because such models cannot by definition encompass this flexibility. Table 6 presents information regarding five long-term credit requests, termed Delta 6 through to Delta 10.

Table 6. SMEs pending credit requests (long-term)

\begin{tabular}{cccccc}
\hline \multicolumn{7}{c}{ SMEs with Pending Credit Requests (Long-Term) } \\
\hline ID Deltas & CTR1 & CTR2 & CTR3 & CTR4 & CTR5 \\
\hline Delta 6 & L1 & L3 & L5 & L2 & L4 \\
\hline Delta 7 & L1 & L4 & L4 & L2 & L4 \\
\hline Delta 8 & L1 & L2 & L3 & L4 & L3 \\
\hline Delta 9 & L1 & L2 & L3 & L3 & L2 \\
\hline Delta 10 & L1 & L2 & L2 & L3 & L4 \\
\hline Good & L1 & L2 & L2 & L2 & L2 \\
\hline Neutral & L2 & L3 & L4 & L3 & L3 \\
\hline
\end{tabular}


Using the AHP scale once more, the next step consisted in analysing the relative importance of each Delta in the diverse criteria, and attributing quantitative values that would allow the ordering of the alternatives with regard to each criterion. Table 7 presents the matrix of judgments resulting from the evaluation made of the five short-term credit requests.

The same exercise was carried out for the five long-term credit requests, as shown in Table 8.

Table 7. Assessment matrix for pending credit requests (short-term)

\begin{tabular}{cccccc}
\hline \multicolumn{7}{c}{ SMEs with Pending Credit Requests (Short-Term) } \\
\hline ID Deltas & CTR1 & CTR2 & CTR3 & CTR4 & CTR5 \\
\hline Delta 1 & 9 & 7 & 4 & 7 & 4 \\
\hline Delta 2 & 9 & 7 & 3 & 4 & 4 \\
\hline Delta 3 & 9 & 7 & 3 & 7 & 3 \\
\hline Delta 4 & 9 & 4 & 7 & 4 & 7 \\
\hline Delta 5 & 9 & 7 & 7 & 3 & 7 \\
\hline
\end{tabular}

Table 8. Assessment matrix for pending credit requests (long-term)

\begin{tabular}{cccccc}
\hline \multicolumn{7}{c}{ SMEs with Pending Credit Requests (Long-Term) } \\
\hline ID Deltas & CTR1 & CTR2 & CTR3 & CTR4 & CTR5 \\
\hline Delta 6 & 9 & 4 & 3 & 7 & 3 \\
\hline Delta 7 & 9 & 3 & 4 & 7 & 3 \\
\hline Delta 8 & 9 & 7 & 5 & 3 & 4 \\
\hline Delta 9 & 9 & 7 & 5 & 4 & 7 \\
\hline Delta 10 & 9 & 7 & 7 & 4 & 3 \\
\hline
\end{tabular}

This information was then introduced in the Sapiens TODIM software (www.comp.ime. eb.br), which applies the mathematical formulae presented in section 2.2. This software allows the values of the matrix of judgments to be directly inserted and so provides much faster final results. Fig. 4 presents the results for the sample of short-term loan requests, as well as the final positions of the Deltas.

As Figure 4 shows, Delta 5 is the credit proposal with the lowest risk. The remaining Deltas present intermediate but decreasing values, all the way to 0 , which corresponds to Delta 4 and is the riskiest of the credit proposals. These standardized global values also show that Deltas 1, 3 and 5 are within the acceptance limits of a credit request, since according to the analysis carried out by our panel of expert decision makers, all credit requests above the refusal rate have high probability of being accepted. Those in the area above the green line (bound 2 on Figure 4) are in the "zone of excellence"; the area between the green and the black lines (bounds 2 and 3 on Figure 4) is considered a "good zone"; the area between the black line and the blue line (bounds 3 and 4 on Figure 4) is considered "acceptable"; while the area below the blue line (bound 4 on Figure 4) is the "zone of refusal". These areas were identified through a process of discussion between the decision makers. 


\begin{tabular}{ccc}
\hline ID & Standardized Global Value & Position \\
\hline Delta 5 & 1.000000 & 1 \\
\hline Delta 3 & 0.918726 & 2 \\
\hline Delta 1 & 0.875906 & 3 \\
\hline Delta 2 & 0.673617 & 4 \\
\hline Delta 4 & 0.000000 & 5 \\
\hline
\end{tabular}

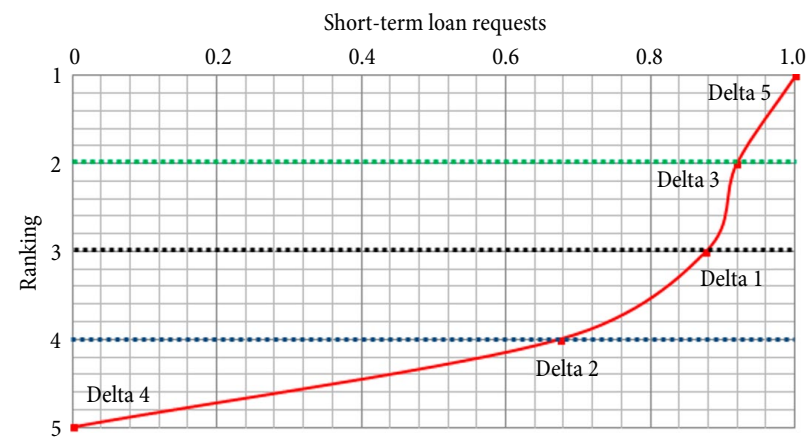

Fig. 4. Standardized global value and respective position (short-term)

They were based on perceptions directly projected by them after group negotiation, exchange of experiences and analysis of the descriptors, as well as cognitive comparisons with Deltas Good and Neutral. Although this procedure is non-linear and inherently subjective, an important feature of the software used to support the process is that it allows for an interactive exploration of changes in the inputs to the model, such that the impact of such changes can be seen immediately, offering opportunities for further discussion; again, a reflection of the constructivist nature of the framework.

In practice, Figure 4 presents a credit scoring system built completely on the basis of the semantic judgments of a group of SME credit specialists. According to these experts, spreads and commissions should be defined on an "all-in" basis, in which the percentage applied varies according to each proposal's credit risk. As such, Delta 5, which is in the "zone of excellence", would obtain a credit concession with a spread of around 5\% to $6 \%$. Delta 3, which is in the "good" zone, would still be granted credit, but with a spread of between $6.1 \%$ and $7.5 \%$, because of its higher level of risk. In the "acceptable" zone, a spread of between $7.6 \%$ and $9 \%$ would be applied, but credit concessions are still possible. Below bound 4, where Deltas 2 and 4 are situated, the credit request would be denied because the risk of default is too high. One should bear in mind that these bounds were set by the decision makers through discussion and negotiation. The same process was applied to the long-term proposals, with different rates. Figure 5 presents the values and relative positions of the long-term credit requests.

As Figure 5 shows, Delta 9 is the lowest risk proposal; and other than this one, only Deltas 10 and 8 are within the range of acceptance. As with the short-term requests, the spreads and commissions are based on an "all-in" logic, which links them to the level of credit risk. Thus, because it is in the "zone of excellence", Delta 9 would have access to credit 


\begin{tabular}{ccc}
\hline ID & Standardized Global Value & Position \\
\hline Delta 9 & 1.000000 & 1 \\
\hline Delta 10 & 0.882365 & 2 \\
\hline Delta 8 & 0.651753 & 3 \\
\hline Delta 6 & 0.101294 & 4 \\
\hline Delta 7 & 0.000000 & 5 \\
\hline
\end{tabular}

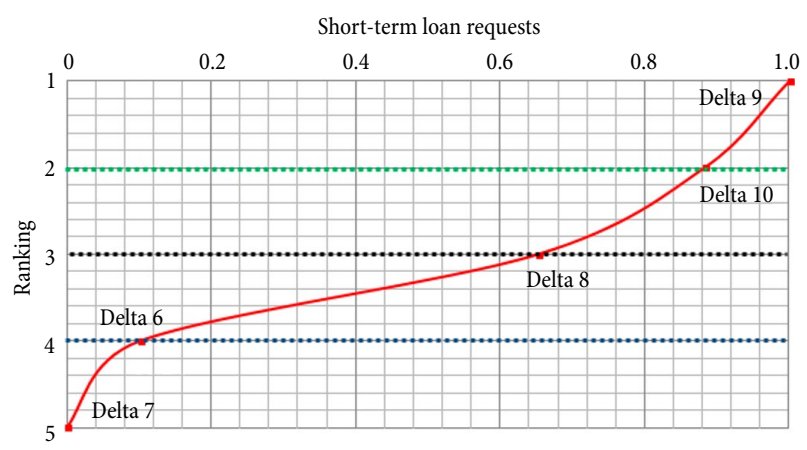

Fig. 5. Standardized global value and respective position (long-term)

with a spread of around $4 \%$ to $5 \%$. Delta 10 is in the "good zone", and would be subject to a spread of between $5.1 \%$ and $5.5 \%$. In the "acceptable" zone, a spread of $5.6 \%$ to $8 \%$ would be applied; and below bound 4, where Deltas 6 and 7 are, credit requests would be denied based on the high risk of default. It is worth noting that this model becomes increasingly more rigorous and precise as new Deltas are introduced, since with more alternatives to compare, error is reduced, and the decision-making process is strengthened.

At the end of the whole process, the experts in the panel showed high levels of satisfaction, recognized the potential of the methods used and considered TODIM an important tool for credit risk assessment. Notwithstanding the value of such feedback, the current study is naturally neither definitive nor binding. The system presented in this paper is idiosyncratic, and should be regarded, first and foremost, as a decision support tool, or even an "important advisor" (in the decision makers' own words). It does not dictate definitive or optimal solutions; and given its idiosyncrasy, extrapolation to other contexts should be carried out with caution. Statistical sensitivity and robustness analyses, for instance, are important but could not be undertaken in the current study due to lack of information regarding more credit requests. In this regard, it should be mentioned that, although we would have liked to work with a larger sample of SME credit applications, the information provided resulted from an administrative decision over which we had no control.

\section{Conclusions}

The results of the present study indicate that multi-criteria methodologies hold great potential for the development of robust, transparent and realistic valuation models. Such methodologies can make an important contribution to credit risk assessments for SMEs, of use 
to both banking agents and SMEs themselves. Given the role of SMEs in many European economies on the one hand, and their dependence on credit concessions on the other, it seems plausible to suggest that such valuation models can potentially impact a country's economy as a whole. The model presented in this paper provided confirmatory evidence for the use of MCDA methodologies in the development of a multiple criteria decision aid system for the evaluation of loan requests by SMEs. Such a system was characterized by its simplicity, robustness, and crucially provided greater transparency than commonly used alternatives. It can be concluded, therefore, that multicriteria methodologies can constitute important tools for the construction of more realistic credit risk assessment models, with positive spillovers not only for the development of the banking activity, at the bank branch level in particular, but potentially for the economy as a whole.

Although there is no one best overall technique for building credit scoring models, it is worth noting that the model developed in the current study allowed for simple and straightforward credit concession decisions, facilitating the evaluation of SME credit applications through informed, comprehensive and transparent risk assessments. Due to its constructivist nature, however, the system developed is endowed with idiosyncratic characteristics, such that its results should not be extrapolated without due caution. Indeed, the aim of this study was not to achieve a unique optimization model, but rather to contribute to the promotion of new methodologies which, on the basis of discussion and negotiation among experts, might improve credit allocation decisions.

With regard to future research, it would be of interest to perform comparisons among different SME credit-scoring systems, including sensitivity and robustness analyses, in order to try to define which model or technique can provide more robust and reliable risk assessments. Our focus in the current research was on the integration of the two techniques applied, and the development and application of the framework thus developed, such that detailed comparisons were beyond the scope of our paper. However, we recognize the potential value of such work and can only encourage such future endeavours.

It should be highlighted, in addition, that our intention in this paper was to adopt a complementary (more so than comparative) perspective because, as we acknowledge in the paper, our proposal is not without its own limitations. Improvements to the system developed in this study would also be of use, as would be the development of a software application that might facilitate the implementation of the proposed procedures. Indeed, given the huge, and largely unexplored potential in this field, any advance in the application of MCDA methodologies should be welcomed as an advance to both theory and practice.

\section{Acknowledgements}

The authors gratefully acknowledge the superb contribution and infinite willingness of the credit experts: António Neves, Nuno Torres and Tiago Valentim. Institutional and facility support from the ISCTE Business School, University Institute of Lisbon, Portugal, is also acknowledged. 


\section{References}

Ackermann, F.; Eden, C. 2001. SODA - Journey making and mapping in practice, in J. Rosenhead, J. Mingers (Eds.). Rational analysis for a problematic world revisited: problem structuring methods for complexity, uncertainty and conflict. $2^{\text {nd }}$ ed. Chichester: John Wiley \& Sons, 43-60.

Altman, E.; Sabato, G. 2007. Modelling credit risk for SMEs: evidence from the US market, Abacus 43(3): 332-357. http://dx.doi.org/10.1111/j.1467-6281.2007.00234.x

Altman, E.; Sabato, G.; Wilson, N. 2010. The value of non-financial information in small and mediumsized enterprise risk management, Journal of Credit Risk 2(6): 95-127.

Altman, E.; Saunders, A. 1998. Credit risk measurement: developments over the last 20 years, Journal of Banking \& Finance 21(11/12): 1721-1742.

Amado, C.; Santos, S; Marques, P. 2012. Integrating the data envelopment analysis and the balanced scorecard approaches for enhanced performance assessment, Omega 40(3): 390-403. http://dx.doi.org/10.1016/j.omega.2011.06.006

Bana e Costa, C.; Stewart, T.; Vansnick, J. 1997. Multicriteria decision analysis: some thoughts based on the tutorial and discussion sessions of the ESIGMA meetings, European Journal of Operational Research 99(1): 28-37. http://dx.doi.org/10.1016/S0377-2217(96)00380-3

Belton, V.; Stewart, T. 2002. Multiple criteria decision analysis: an integrated approach. Dordrecht: Kluwer Academic Publishers. http://dx.doi.org/10.1007/978-1-4615-1495-4

Campbell, J.; Hilscher, J.; Szilagyi, J. 2008. In search of distress risk, The Journal of Finance 63(6): 2899-2939. http://dx.doi.org/10.1111/j.1540-6261.2008.01416.x

Carlucci, D.; Schiuma, G.; Gavrilova, T.; Linzalone, R. 2013. A fuzzy cognitive map based approach to disclose value creation dynamics of ABIs, in Proceedings of the $8^{\text {th }}$ International Forum on Knowledge Asset Dynamics (IFKAD-2013), 12-14 June 2013, Zagreb, Croatia, 207-219.

Chaia, J. 2003. Modelos de gestão de risco de crédito e a sua aplicabilidade ao mercado brasileiro: MSc Dissertation in Business Administration, University of São Paulo, Brazil.

Costa, C. 2004a. Estratégias bancárias e a avaliação do risco de crédito, in Proceedings of the PortugueseSpanish Conference on Scientific Management, 4-7 February 2004, Azores, Portugal, 1090-1097.

Costa, C. 2004b. Métodos Qualitativos na análise de risco de crédito: confiança e credibilidade na relação entre bancos e empresas [online], [cited May 2013]. Available from Internet: http://www1.eeg. uminho.pt/economia/caac/pagina\%20pessoal/papers/WPC2A-QUALIT.PDF

Doumpos, M.; Zopounidis, C. 2001. Assessing financial risks using a multicriteria sorting procedure: the case of country risk assessment, Omega 29(1): 97-109.

http://dx.doi.org/10.1016/S0305-0483(00)00028-1

Eden, C. 1994. Cognitive mapping and problem structuring for system dynamics model building, System Dynamics Review 10(3): 257-276. http://dx.doi.org/10.1002/sdr.4260100212

Eden, C.; Ackermann, F. 2001. SODA - the principles, in J. Rosenhead, J. Mingers. (Eds.). Rational analysis for a problematic world revisited: problem structuring methods for complexity, uncertainty and conflict. $2^{\text {nd }}$ ed. Chichester: John Wiley \& Sons, 21-41.

Eden, C.; Ackermann, F. 2004. Cognitive mapping expert views for policy analysis in the public sector, European Journal of Operational Research 152(3): 615-630. http://dx.doi.org/10.1016/S0377-2217(03)00061-4

Ferreira, F. 2011. Avaliação multicritério de agências bancárias: modelos e aplicações de análise de decisão. 1st ed. Faro: University do Algarve Press.

Ferreira, F.; Santos, S.; Dias, V. 2014c. An AHP-based approach to credit risk evaluation of mortgage loans, International Journal of Strategic Property Management 18(1): 38-55.

http://dx.doi.org/10.3846/1648715X.2013.863812 
Ferreira, F.; Santos, S.; Marques, C.; Ferreira, J. 2014a. Assessing credit risk of mortgage lending using MACBETH: a methodological framework, Management Decision 52(2): 182-206. http://dx.doi.org/10.1108/MD-01-2013-0021

Ferreira, F.; Santos, S.; Rodrigues, P. 2011. Adding value to branch performance evaluation using cognitive maps and MCDA: a case study, Journal of the Operational Research Society 62(7): 1320-1333. http://dx.doi.org/10.1057/jors.2010.111

Ferreira, F.; Santos, S.; Rodrigues, P.; Spahr, R. 2014b. Evaluating retail banking service quality and convenience with MCDA techniques: a case study at the bank branch level, Journal of Business Economics and Management 15(1): 1-21. http://dx.doi.org/10.3846/16111699.2012.673504

Ferreira, F.; Spahr, R.; Gavancha, I.; Çipi, A. 2013. Readjusting trade-offs among criteria in internal ratings of credit-scoring: an empirical essay of risk analysis in mortgage loans, Journal of Business Economics and Management 14(4): 715-740. http://dx.doi.org/10.3846/16111699.2012.666999

Fiedler, F. 1965. Engineer the job to fit the manager, Harvard Business Review 43(5): 115-122.

Fiedler, F. 1967. A theory of leadership effectiveness. New York: McGraw-Hill.

Gomes, F.; Rangel, L. 2009. An application of the TODIM method to the multicriteria rental evaluation of residential properties, European Journal of Operational Research 193(1): 204-211. http://dx.doi.org/10.1016/j.ejor.2007.10.046

Gomes, L.; Lima, M. 1991. TODIM: basics and application to multicriteria ranking of projects with environmental impacts, Foundations of Computing and Decision Science 16(4): 113-127.

Gupta, J.; Gregoriou, A.; Healy, J. 2014a. Forecasting bankruptcy for SMEs using hazard function: to what extent does size matter? Review of Quantitative Finance and Accounting (in press). http://dx.doi.org/10.1007/s11156-014-0458-0

Gupta, J.; Wilson, N.; Gregoriou, A.; Healy, J. 2014b. The value of operating cash flow in modelling credit risk for SMEs, Applied Financial Economics 24(9): 649-660.

http://dx.doi.org/10.1080/09603107.2014.896979

Kahneman, D.; Tversky, A. 1979. Prospect theory: an analysis of decision under risk, Econometrica 47(2): 263-292. http://dx.doi.org/10.2307/1914185

Lopez, J.; Saidenberg, M. 2000. Evaluating credit risk models, Journal of Banking \& Finance 24(1): 151-165. http://dx.doi.org/10.1016/S0378-4266(99)00055-2

Mateu, A. 2002. ClusDM: a multiple criteria decision making method for heterogeneous data set: $\mathrm{PhD}$ thesis. Polytechnic University of Catalunya, Spain.

Montibeller, G.; Belton, V. 2006. Causal maps and the evaluation of decision options: a review, Journal of the Operational Research Society 57(7): 779-791. http://dx.doi.org/10.1057/palgrave.jors.2602214

Pereira, J.; Gomes, L.; Paredes, F. 2013. Robustness analysis in a TODIM-based multicriteria evaluation model of rental properties, Technological and Economic Development of Economy 19(Supplement 1): S176-S190. http://dx.doi.org/10.3846/20294913.2014.880753

Rangel, L.; Gomes, L. 2007. Determinação do valor de referência do aluguel de imóveis residenciais empregando o método TODIM, Pesquisa Operacional 27(2): 357-372. http://dx.doi.org/10.1590/S0101-74382007000200009

Ribeiro, L.; Passos, A.; Teixeira, M. 2012. Seleção de tecnologias de comunicações no exército brasileiro utilizando os métodos multicritério de análise hierárquica, TODIM e software Sapiens, Produção 32(1): 132-141. http://dx.doi.org/10.1590/S0103-65132011005000063

Saaty, T. 1980. The analytic hierarchy process: planning, priority setting, resource allocation. New York: McGraw-Hill.

Santos, S.; Belton, V.; Howick, S. 2002. Adding value to performance measurement by using systems dynamics and multicriteria analysis, International Journal of Operations \& Production Management 22(11): 1246-1272. http://dx.doi.org/10.1108/01443570210450284 
Silva, R.; Brandalise, N.; Carneiro, C. 2011. Utilizando o método TODIM para avaliar as melhores empresas para trabalhar, Independent Journal of a Management \& Production 2(1): 1-7. http://dx.doi.org/10.14807/ijmp.v2i1.25

Wang, G.; Hao, J.; Ma, J.; Jiang, H. 2011. A comparative assessment of ensemble learning for credit scoring, Expert Systems with Applications 38(1): 223-230. http://dx.doi.org/10.1016/j.eswa.2010.06.048

$\mathrm{Wu}, \mathrm{H} .2012$. Constructing a strategy map for banking institutions with key performance indicators of the balanced scorecard, Evaluation and Program Planning 35(3): 303-320. http://dx.doi.org/10.1016/j.evalprogplan.2011.11.009

Xiao-yan, Z.; Yan-lei, Q.; Peilong, S. 2012. Review of the international financial trends in post financial crisis era, Procedia Engineering 15: 4795-4799. http://dx.doi.org/10.1016/j.proeng.2011.08.896

Zavadskas, E.; Turkis, Z. 2011. Multiple criteria decision making (MCDM) methods in economics: an overview, Technological and Economic Development of Economy 17(2): 397-427.

http://dx.doi.org/10.3846/20294913.2011.593291

Tânia S. H. GONÇALVES works in the private sector as a credit analyst and ICT technician. Her research interests include finance, accounting and decision support systems (DSS). Some of her works have been presented in national and international events.

Fernando A. F. FERREIRA is Assistant Professor and Vice-Dean for financial affairs at the ISCTE Business School of the University Institute of Lisbon, and Adjunct Research Professor at the Fogelman College of Business and Economics of the University of Memphis, TN, USA. He holds a PhD in Quantitative Methods Applied to Economics and Management from the University of Algarve, Portugal. Some of his articles are published by ISI-listed journals such as Journal of the Operational Research Society, Management Decision, Journal of Business Research, and International Journal of Strategic Property Management. He has practical experience as a group facilitator and his research interests include multiple criteria decision analysis, fuzzy logics and integrated systems for performance measurement.

Marjan S. JALALI is Assistant Professor at the ISCTE Business School of the University Institute of Lisbon, and researcher at the Business Research Center (BRU-IUL), Portugal. She holds a PhD in Management from the University of Sydney, Australia. She is an editorial board member of the Global Business and Economics Review, managing editor of the International Journal of Management Science and Information Technology, and some of her works have been published nationally and internationally. Her research interests include multiple criteria decision analysis, strategic decision making and consumer behaviour.

Ieva MEIDUTE்-KAVALIAUSKIENE் is Associate Professor and Vice-Dean at the Faculty of Business Management of the Vilnius Gediminas Technical University, Lithuania. She holds a PhD in Technological Science from the Vilnius Gediminas Technical University. She has authored peer-reviewed papers and some of her works have been presented and published nationally and internationally. She is an editorial board member of several international journals, and her research interests include logistics and operations management. 